\title{
Betonarme Binalarda Perde Yeri Değișiminin Bina Performansına Etkisi
}

\author{
S1la Yaman ${ }^{1 *}$, Hamide Tekeli ${ }^{2}$, Fuat Demir ${ }^{3}$ \\ ${ }^{1}$ Süleyman Demirel Üniversitesi, Mühendislik Fakültesi, İnşaat Mühendisliği Bölümü, Isparta, Türkiye (ORCID: 0000-0003-3131-1090) \\ ${ }^{2}$ Süleyman Demirel Üniversitesi, Mühendislik Fakültesi, İnşaat Mühendisliği Bölümü, Isparta, Türkiye (ORCID: 0000-0002-3515-6836) \\ ${ }^{3}$ Süleyman Demirel Üniversitesi, Mühendislik Fakültesi, İnşaat Mühendisliği Bölümü, Isparta, Türkiye (ORCID: 0000-0001-6726-3831)
}

(İlk Geliş Tarihi 18 Şubat 2019 ve Kabul Tarihi 15 Mayıs 2019)

(DOI: 10.31590/ejosat.528665)

ATIF/REFERENCE: Yaman, S., Tekeli, H. \& Demir, F. (2019). Betonarme Binalarda Perde Yeri Değişiminin Bina Performansına Etkisi. Avrupa Bilim ve Teknoloji Dergisi, (16), 194-204.

\section{$\ddot{O} \mathbf{z}$}

Betonarme binalarda deprem etkisine karşı perde duvar kullanımının önemi büyüktür. Tasarım aşamasında uygulamacı mühendisler, planda yerleştirilecek olan perde duvar miktarına ve yerleşimine karar verir. Bunun için öncelikle, perde duvar miktarı ve yerleşimi parametrelerinin, bina davranışı ve deprem güvenliği üzerindeki etkilerinin anlaşılması gerekmektedir. Bu çalışmada; betonarme bir binanın planındaki perde duvar yerleşimi farklılı̆̆ının binanın kapasitesi ve deprem performansı üzerindeki etkisi incelenmiştir. Bu amaçla, konut türü, sekiz katlı, iki ve dört açıklıklı, farklı perde duvar miktar ve yerleşimlerine sahip perdeli çerçeveli ve sadece çerçeveli betonarme binalar model olarak seçilmiştir. Model binalar düzenli bir kalıp planına sahiptir. Perde duvarlar, diğer yönde yerleştirilecek perdelerin binanın çözümleme sonuçlarına olan etkisi ihmal edilerek, binanın sadece x doğrultusunda simetrik olacak şekilde yerleştirilmiştir. Model binalarda kullanılan perde kesiti DBYBHY (2007)'de verilen minimum boyutları sağlayacak şekilde $200 \times 1400 \mathrm{~mm}$ olarak dikkate alınmıştır. Çalışma kapsamında perde duvarlar, geniş kolon analojisi olarak da bilinen plastik mafsallı orta-dikme çubuk modeli kullanılarak SAP 2000 programı ile modellenmiştir. Tüm model binaların deprem performans değerlendirmeleri doğrusal elastik olmayan yöntemlerden “Artımsal Eşdeğer Deprem Yükü Yöntemi” kullanılarak yapılmıştır. Model binalar için kapasite eğrileri, performans seviyeleri ve perde duvarda meydana gelen kesme kuvveti ve moment grafikleri elde edilmiştir. Çalışma kapsamında elde edilen sonuçlardan, perde duvarların iç ya da dış aksa yerleştirilmesinin, binanın kesme kapasitesinde $\% 2$ oranında bir değişime neden olduğu görülmüştür. Yapılan çözümlemelerde sekiz katlı ve taşıyıcı sistemi salt çerçeveli olarak oluşturulan bina modellerinin hiçbirinin hedef performans seviyesini sağlamadığı görülmüştür. Bina planına simetrik olarak perde duvar yerleştirilmesi, performans seviyesinin hedef performans seviyesine yükseltilmesini sağlamıştır. Dolayısıyla perde miktarı ve yerleşimi değiştirilen tüm bina çözümlemelerinde, "Can Güvenliği”" performans seviyesi elde edilmiştir.

Anahtar Kelimeler: Betonarme bina, performans, perde duvar, doğrusal elastik olmayan yöntem.

\section{The Effects of Shear Wall Location on Building Performance in Reinforced Concrete Buildings}

\begin{abstract}
The use of a shear wall in reinforced concrete buildings is of great importance against earthquake effect. At the design stage, the application engineers decide the amount and location of the shear wall to be used in the plan. Therefore, first of all, it is should be understood the effects of the shear wall quantity and layout parameters on the building behavior and seismic safety. In this study; the variation of shear wall layout in the plan of a reinforced concrete building is investigated on the effects of building capacity and seismic performance. For this purpose, a residential type, eight-storeyed, two and four-span shear wall frame, and only frame reinforced concrete buildings are selected as models. The model buildings have a regular formwork plan. The shear walls have been
\end{abstract}

\footnotetext{
* Sorumlu Yazar: Süleyman Demirel Üniversitesi, Mühendislik Fakültesi, İnşaat Mühendisliği Bölümü, Isparta, Türkiye, ORCID: 0000-0003-31311090, silayaman@sdu.edu.tr
} 
placed in such a way that they will be symmetrical in the x-direction of the building neglecting the effect of the shear walls that will be placed in the other direction on the results of the analysis of the building. The shear wall section used in the model buildings has been considered as $200 \times 1400 \mathrm{~mm}$ in such a way that it will ensure the minimum dimensions given in DBYBHY (2007). Within the scope of the study, the shear walls, also known as wide column analogy, have been modeled in SAP2000 program by using a plastic hinged mid-strut rod model. The seismic performance evaluations of all model buildings were made by using "Incremental Equivalent Seismic Load Method" of nonlinear elastic methods. Capacity curves, performance levels, and graphs of shear force and bending moment that occurred on the shear wall were obtained for the model buildings. From the results obtained in this study, it has been observed that the placement of the shear walls on the inner or outer axis caused a change in shear capacity of the building by $2 \%$. In the analyzes made, it was seen that none of the building models, which were formed as an eight-storeyed and purely framed system, ensured the target performance level. Placing the shear wall symmetrically on the building plan has ensured the performance level to be increased to the target performance level. Therefore, "Life Safety" performance level is obtained in all building analyzes where shear wall quantity and location is changed.

Keywords: Reinforced concrete building, performance, shear wall, nonlinear analysis.

\section{Giriş}

Ülkemiz nüfusunun \%95'i ve büyük sanayi merkezlerinin neredeyse tamamı deprem riski etkisinde olduğundan (Öztürk, 2005), bu bölgelerde bulunan binaların depreme güvenli olarak inşaa edilmesi gerekmektedir. Bir binanın deprem güvenliğine en çok katkı sağlayan taşıyıcı elemanlar perde duvarlardır (Atımtay, 2000).

Depremde hasar gören binalar üzerinde yapılan incelemelerde, perdeli binaların çerçeveli binalara göre performansının daha iyi olduğu gözlenmiştir (Şahin ve ark., 2013). Betonarme binalarda deprem etkisine karşı perde duvar kullanımının önemi büyüktür. Perdeli çerçeveli sistemlerde kat kesme kuvvetinin büyük bir bölümü perdeler tarafindan karşılanmakta, kolonlara etkiyen kesme kuvveti büyük oranda azalmaktadır (Kasap ve ark., 2015). Özellikle yüksek katlı binaların tasarımında, yatay yüklerin karşılanması ve yerdeğiştirmelerin sınırlandırılması için perde duvarların kullanılması önemlidir. Tasarım aşamasında uygulamacı mühendisler, planda yerleştirilecek olan perde duvar miktarına ve yerleşimine karar verir. Bunun için öncelikle, perde duvar miktarı ve yerleşimi parametrelerinin, bina davranışı ve deprem güvenliği üzerindeki etkilerinin anlaşılması gerekmektedir. Perde miktarı değişiminin davranış üzerindeki etkileri ile ilgili yapılan bazı çalışmalarda, perde oranı arttıkça kolonlarda hasara sebep olan plastik dönme miktarının azaldığı ya da tamamen kaybolduğu ve binada hedeflenen performans düzeyinin sağlanmasında önemli rol oynadığı gözlenmiştir (Kasap ve Varol, 2003; Günel, 2013; Sakcalı ve ark., 2017; Yüksel ve ark., 2017).

Bina planında perde duvar yerleşiminin değişmesiyle meydana gelen davranış farklılıklarını incelemek amacıyla yapılan çalışmalarda (Uçar ve Merter, 2009; Aktan ve Kıraç, 2010; Halkude ve ark., 2015; Rokanuzzaman ve ark., 2017; Yaman, 2018), perde duvarların dış aksa yerleştirilmesinin davranış açısından daha uygun olduğu, kat yatay yerdeğiştirmelerinin oldukça azaldığı ve burulma rijitliğinin arttığı ifade edilmiştir. Ancak yapılan bu incelemelerde doğrusal olmayan davranış genellikle gözardı edilmiştir. Son yıllarda binaların deprem güvenliği incelemesinde kullanılan doğrusal elastik ve doğrusal elastik olmayan yöntemlerin yaygın olması ile incelemeler bu alanlarda yoğunlaşmıştır. Örneğin Sayın ve ark. (2010) tarafından yapılan çalışmada, çok katlı betonarme binaların zemin sınıfı değişiminin ve farklı perde konumunun taşıyıcı elemanların hasarına etkisi, doğrusal elastik değerlendirme yöntemi kullanılarak incelenmiştir. Elde edilen sonuçlardan, perde duvarların yapının dış akslarından iç akslara doğru kaydırılması ve zemin sınıfının Z1' den Z4' e doğru değişim göstermesi ile yapı elemanlarındaki iç kuvvetlerin ve hasarların arttığı gözlenmiştir. Benzer sonuçlar, Aracı (2012) tarafından doğrusal elastik değerlendirme yöntemi kullanılarak yapılan çalışmada da sunulmuş ve perde duvarların olabildiğince kat planının dış çerçevesine ve simetrik olarak yerleştirilmesi tavsiye edilmiştir. Firoozabad ve ark. (2012), perde duvar yerleşiminin çatı katı ötelenmesi üzerindeki etkisini incelemek amacıyla, farklı kat adedine ve perde yerleşimlerine sahip binaları, Zaman Tanım Alanında Hesap Yöntemini kullanarak çözümlemiştir. Elde edilen sonuçlardan, perde duvar konumunun değişiminin çatı katı ötelenme değerlerini \%100 oranında değiştirebildiği görülmüştür. Öztürk ve ark. (2017) tarafından yapılan çalışmada, Zaman Tanım Alanında doğrusal olmayan dinamik analizlerin yapılması ile perdeli-çerçeveli modelde meydana gelen yerdeğiştirmelerin, çerçeveli modele göre beklenildiği gibi daha düşük seviyelerde olduğu görülmüştür.

Bu çalışmada, plandaki perde duvar yerleşimi farklılığının, betonarme binaların deprem performansına olan etkisi doğrusal elastik olmayan yöntemler arasından “Artımsal Eşdeğer Deprem Yükü Yöntemi” kullanılarak incelenmiştir. Bu amaçla düzenli taşıyıcı sisteme sahip konut türü model binalar seçilmiştir. Bu binalara DBYBHY (2007)’de verilen minimum boyutları sağlayacak şekilde simetrik olarak, farklı miktarlarda ve yerleşimlerde perde duvarlar ilave edilerek perdeli-çerçeveli bina modelleri oluşturulmuştur. Tüm binaların deprem güvenliği doğrusal elastik olmayan yöntem ile belirlenmiştir.

\section{Materyal ve Metot}

\subsection{Deprem Güvenliği Belirlenmesinin Esasları}

Mevcut binanın deprem performansına karar verebilmek için, DBYBHY (2007)' in yedinci bölümünde doğrusal elastik ve doğrusal elastik olmayan hesap yöntemlerinden en az birinin uygulanması önerilmektedir. Betonarme binaların deprem güvenliğinin belirlenmesi için çalışma kapsamında yapılan çözümlemelerde DBYBHY (2007)'de tanımlanan doğrusal elastik olmayan değerlendirme yöntemlerinden “Artımsal Eşdeğer Deprem Yükü Yöntemi İle İtme Analizi” yöntemi kullanılmıştır. Artımsal Eşdeğer Deprem Yükü Yöntemi’nin uygulanabilmesi için binanın kat adedinin sekizden az olması, burulma düzensizliği katsayısının 1.4 değerinden küçük olması, birinci titreşim moduna ait etkin kütlenin toplam bina kütlesine oranının en az 0.70 olması gereklidir. 
Yönetmelikte sunulan doğrusal elastik olmayan hesap yöntemlerinin amacı, belli bir deprem seviyesi için sünek davranışa ilişsin plastik şekildeğiştirme istemleri ile gevrek davranışa ilişkin iç kuvvet istemlerinin hesaplanması olarak belirtilmiştir. Bu istem büyüklükleri, şekildeğiştirme ve iç kuvvet kapasiteleri ile karşılaştırılarak, kesit ve bina düzeyinde performans değerlendirmesi yapılır. Bunun için öncelikle, kesitlere ait plastik mafsallar atanır ve artan yanal yük altında kapasite eğrisi elde edilir. Kapasite eğrisinin koordinatları, "modal yerdeğiştirme-modal ivme" eğrisi koordinatlarına, spektrum eğrisinin koordinatları ise "spektral ivmespektral yerdeğiştirme" eğrisi koordinatlarına dönüştürülür. Eksen dönüşümleri yapılan her iki eğri aynı grafik üzerinde çizilerek binaya ait hedef yerdeğiştirme istem seviyesi belirlenir. Binanın çatı katının hedef yerdeğiştirme istem seviyesine kadar ötelenmesi durumunda, taşıyıcı elemanlarda elde edilen beton ve donatıya ait şekildeğiştirme değerleri, DBYBHY (2007)'de tanımlanan sınır değerlerle kıyaslanarak eleman hasar seviyeleri belirlenir.

DBYBHY (2007)'de sünek elemanlar için kesit düzeyinde üç farklı hasar sınır durumu tanımlanmıştır. Bunlar Minimum Hasar Sınırı (MN), Güvenlik Sınıı (GV) ve Göçme Sınırı (GÇ)'dır. Plastik şekildeğiştirmelerin hasar seviyesi için izin verilen üst sınırları Eşt. 1,2 ve 3 'te verilmiştir.

$\left(\varepsilon_{\mathrm{cu}}\right)_{\mathrm{MN}}=0.0035 ;\left(\varepsilon_{\mathrm{s}}\right)_{\mathrm{MN}}=0.01$

$\left(\varepsilon_{\mathrm{cg}}\right)_{\mathrm{GV}}=0.0035+0.01\left(\rho_{\mathrm{s}} / \rho_{\mathrm{sm}}\right) \leq 0.0135 ;\left(\varepsilon_{\mathrm{s}}\right)_{\mathrm{GV}}=0.040$

$\left(\varepsilon_{\mathrm{cg}}\right)_{\mathrm{GC}}=0.004+0.014\left(\rho_{\mathrm{s}} / \rho_{\mathrm{sm}}\right) \leq 0.018 ;\left(\varepsilon_{\mathrm{s}}\right)_{\mathrm{GC}}=0.060$

Burada $\varepsilon_{c}$, beton basınç birim şekildeğiştirmesinin üst sınıını; $\varepsilon_{s}$, donatı çeliği birim şekildeğiştirmesinin üst sınırını; $\rho_{\mathrm{s}}$, kesitte mevcut olan ve $\rho_{\mathrm{sm}}$ ise kesitte bulunması gereken enine donatının hacimsel oranını göstermektedir.

Betonarme taşıyıcı elemanlar için, DBYBHY (2007)'de dört farklı hasar bölgesi tanımı yapılmıştır. Kritik kesitlerinin hasarı MN'ye ulaşmayan elemanlar Minimum Hasar Bölgesi'nde, MN ile GV arasında kalan elemanlar Belirgin Hasar Bölgesi'nde, GV ve GÇ arasında kalan elemanlar İleri Hasar Bölgesi’nde, GÇ’yi aşan elemanlar ise Göçme Bölgesi’nde yer alırlar (Şekil 1).

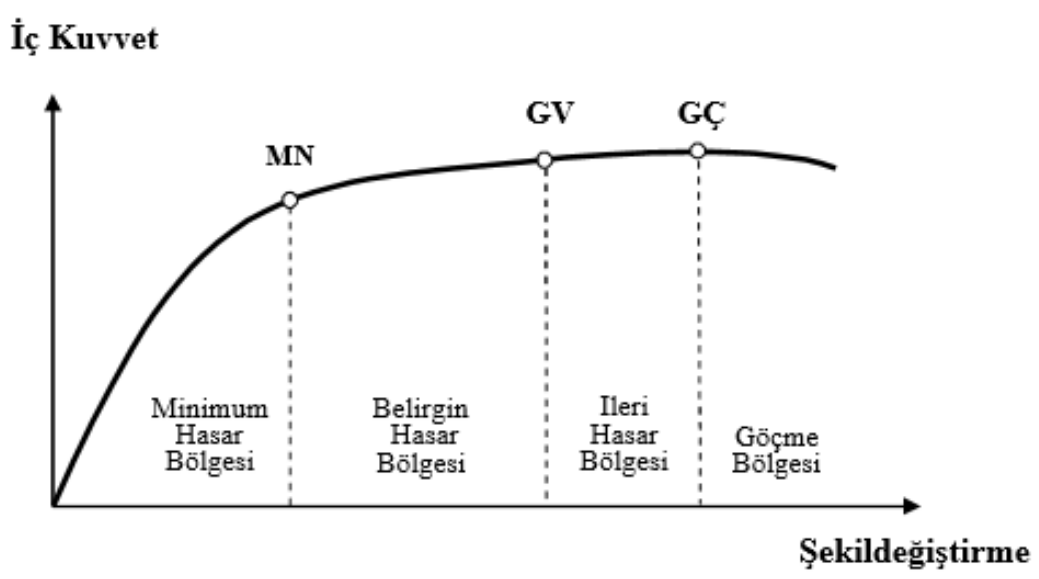

Şekil 1. Kesit hasar bölgeleri (DBYBHY, 2007)

Kat içerisindeki taşıyıcı sistem elemanlarının hasar seviyelerinin dağılımına bağlı olarak kat performans seviyesi, kat performans seviyelerinin kıyaslanması ile bina performans seviyesi elde edilir. DBYBHY (2007)'de deprem etkisi altında binada oluşması beklenen performans seviyesi Hemen Kullanım, Can Güvenliği, Göçme Öncesi ve Göçme Durumu olmak üzere dört farklı şekilde tanımlanmıştır. Binanın depreme karşı güvenlik durumuna; binaya ait elde edilen deprem performans seviyesinin, bina kullanım amacı ve deprem düzeyine göre belirlenen hedef performans seviyesi ile kıyaslanmasıyla karar verilir. Çalışma kapsamında konut türü binaların deprem güvenliği incelendiği için, hedef performans seviyesi olarak 50 yılda aşılma olasıllğı \%10 olan deprem için "Can Güvenliği”" performans seviyesi seçilmiştir. Bu performans seviyesinin sağlanması için DBYBHY (2007)'de verilen koşullar aşağıda tanımlanmıştır.

“(a) Kirişlerin en fazla \%30’u İleri Hasar Bölgesi’ne geçebilir.

(b)İleri Hasar Bölgesi'ndeki kolonların, her bir katta kolonlar tarafindan taşınan kesme kuvvetine toplam katkısı \%20'nin altında olmalıdır. En üst katta bu oran en fazla \%40 olabilir.

(c) Diğer taşlyıcı elemanların tümü Minimum Hasar Bölgesi veya Belirgin Hasar Bölgesi'ndedir. Ancak, herhangi bir katta alt ve üst kesitlerinin ikisinde birden Minimum Hasar Sinırı aşılmış olan kolonlar tarafindan taşınan kesme kuvvetlerinin, o kattaki tüm kolonlar tarafindan taşınan kesme kuvvetine oraninın \%30'u aşmaması gerekir."

\subsection{Bina Modellerinin Tanıtılması}

Betonarme konut türü bir binanın planındaki perde duvar yerleşimi farklılığının bina performansı üzerindeki etkisini incelemek amacıyla, düzenli ve simetrik bir plana sahip $2 \times 2$ ve $4 \times 4$ açıklıklı çerçeveli binalar model olarak seçilmiştir. Çerçeveli binalara farklı yerleşimde ve miktarda perde duvarlar ilave edilerek perdeli-çerçeveli bina modelleri elde edilmiştir. Perde duvarlar, diğer yönde yerleştirilecek perdelerin binanın çözümleme sonuçlarına olan etkisi ihmal edilerek, binanın sadece x doğrultusunda simetrik olacak şekilde yerleştirilmiştir. Burada amaç perde miktarı ve yerleşiminin daha kolay bir şekilde değiştirilmesini sağlamak ve bu 
parametrelerin, sistemin çözümleme sonuçlarına olan etkisini incelemektir. Bu nedenle perde duvarlar sisteme tek doğrultuda yerleştirilmiş ve binalar SAP 2000 programı (2011) yardımıyla bu doğrultuda çözümlenmiştir. Oluşturulan $2 \times 2$ açıklıklı bina planlarına ait görünümler Şekil 2'de, $4 \times 4$ açıklıklı bina planlarına ait görünümler ise Şekil 3 'te verilmişsir.

(a)

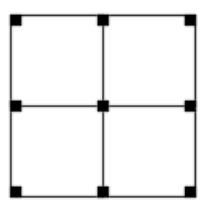

(b)

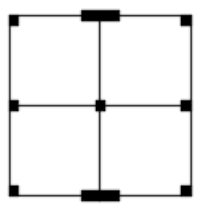

(c)

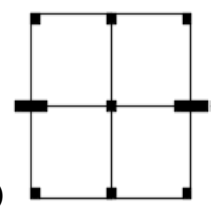

(d)

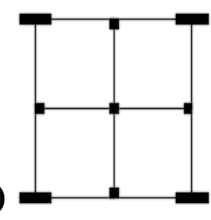

(e)

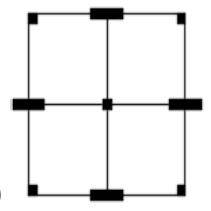

Şekil 1. İki açıklıklı model binalara ait kalıp planı görünümleri (a) Model 1_A2_C, (b) Model 2_A2_P2, (c) Model 3_A2_P2, (d) Model 4_A2_P4 ve (e) Model 5_A2_P4

(a)

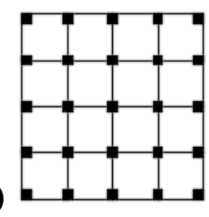

(b)

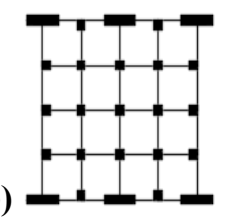

(c)

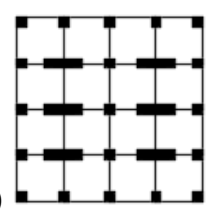

Şekil 2. Dört açıklıklı model binalara ait kalıp planı görünümleri (a) Model 6_A4_Ç, (b) Model 7_A4_P6 ve (c) Model 8_A4_P6

Burada, Model 2_A2_P2 isimlendirmesinde kullanılan Model_2 ifadesi, 2 numaralı modeli; A2 ifadesi, 2×2 açıklıklı modeli; P2 ifadesi ise kullanılan perde sayısının 2 olduğunu göstermektedir. Modellerden birincisi salt çerçeveli sistemden oluşmaktadır. Diğer modeller ise, farklı miktarda ve yerleşimlerdeki perdenin ilave edildiği sistemleri ifade etmektedir. Tüm modeller sekiz katlı olarak tasarlanmış, kat yükseklikleri $3 \mathrm{~m}$, $\mathrm{x}$ ve y doğrultusundaki taşıyıcı sistem eksen açıklıkları ise $4 \mathrm{~m}$ olarak seçilmiştir. Model binalarda kullanılan perde kesiti DBYBHY (2007)'de verilen minimum boyutları sağlayacak şekilde $200 \times 1400 \mathrm{~mm}$ olarak dikkate alınmıştır. Çözümlemelerde dikkate alınan perde kesiti ve donatısı Şekil 4'te verilmiş̧ir.

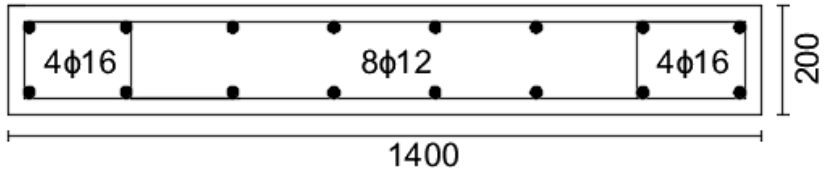

Şekil 4. Perde duvara ait kesit özellikleri $(\mathrm{mm})$

Model binaların, 1. derece deprem bölgesinde ve Z4 yerel sınıfinda bulunan konut türü binalar olduğu kabul edilmiştir. Sistemin simetrik olmasından dolayı, çözümlemeler sadece binanın x yönü için yapılmıştır. Tüm modellerde, kiriş boyutu $250 \times 500 \mathrm{~mm}$, kolon boyutu ise $450 \times 450 \mathrm{~mm}$ olarak dikkate alınmıştır. Kolona ait donatı oranı \%1.2 (8Ø20) olarak seçilmiştir. Kirişlerde mesnet üst donatısı 8Ø16, alt donatısı ise $4 \varnothing 16$ olarak dikkate alınmıştır. Taşıyıcı sistem elemanlarının mesnet bölgelerinde etriye Ø8/10 olarak kullanılmıştır. Kolon ve kiriş kesitlerine ait görünüm Şekil 5'te verilmiş̧ir. Modellenen binalarda rijit diyafram etkisi tüm katlar için dikkate alınmıştır. Çözümlemelerde C20 beton ve S420 donatı sınıfı esas alınmıştır. Performans değerlendirmeleri "Artımsal Eşdeğer Deprem Yükü Yöntemi” kullanılarak yapılmıştır. Yönetmelik esaslarının kontrol edilebilmesi için, Doğrusal Elastik Olmayan Değerlendirme Programı (DELOP, 2013) kullanılmıştır.

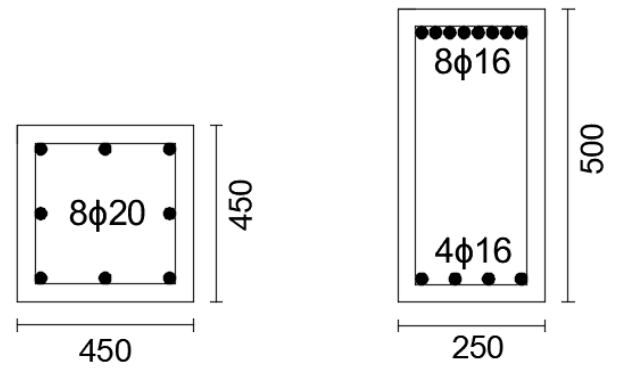

Şekil 5. Kolon ve kirişe ait kesit özellikleri $(\mathrm{mm})$

Binanın yatay yük taşıma kapasitesini ve yanal ötelenme rijitliğini önemli derecede artıran perde duvarların yapısal analizlerinin gerçekçi bir şekilde yapılabilmesi için doğru şekilde modellenmesi büyük önem taşımaktadır (Fahjan ve ark., 2011). Çalışma kapsamında perde duvarlar, geniş kolon analojisi olarak da bilinen plastik mafsallı orta-dikme çubuk modeli kullanılarak 
tanımlanmıştır. Bu modelde perde duvar, perde akslarından geçen geniş bir kolon olarak modellenmektedir (Şekil 6). Perdenin (B) genişliğince oluşan eşit dönme açısı, uzunlukları perde kesit genişliğinin yarısına eşit $(\mathrm{B} / 2)$ ve eğilme rijitliği sonsuz olan kiriş elemanların kullanılmasıyla sağlanır (Atımtay, 2001).

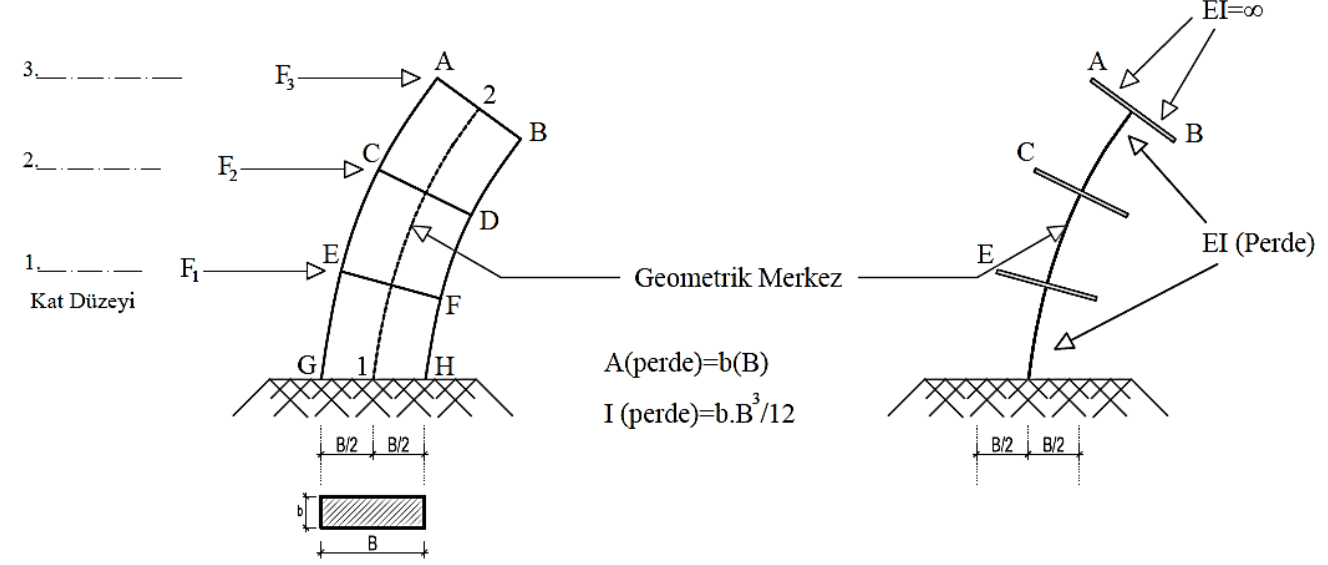

Şekil 6. Perde taşıyıcının eşdeğer matematik modeli (Sakcalı ve ark., 2017)

Doğrusal olmayan çözümlemenin yapılabilmesi için, kolon ve perde elemanlara PM2M3, kiriş elemanlara ise M3 mafsalları atanmıştır. Plastik mafsallar, kolon ve kirişlerde net açıklıklarının uçlarına, perde elemanlarda plastik şekildeğiştirme bölgesinin tam ortasına yerleştirilmiştir (Şekil 7). Mafsal özelliklerinin tanımlanmasında Betonarme Elemanlarda Sargı ve Modelleme (BESAM, 2013) programı kullanılmıştır. BESAM, betonarme elemanlarda beton dayanımı, donatı düzeni ve sargı etkisini dikkate alarak kesit özelliklerini tanımlamak için Fortran dilinde yazılan bir bilgisayar programıdır. Programda, sargılı beton modeli için DBYBHY (2007)'de verilen Mander sargı modeline ait gerilme-ş̧ekildeğiştirme iliş̧kileri kullanılmaktadır. Beton için sargılı model kullanılarak kiriş ve kolon kesitine ait moment-eğrilik ve moment-dönme ilişkileri, kolon ve perde duvar kesitine ait karşlıklı etki diyagramları elde edilebilmektedir.

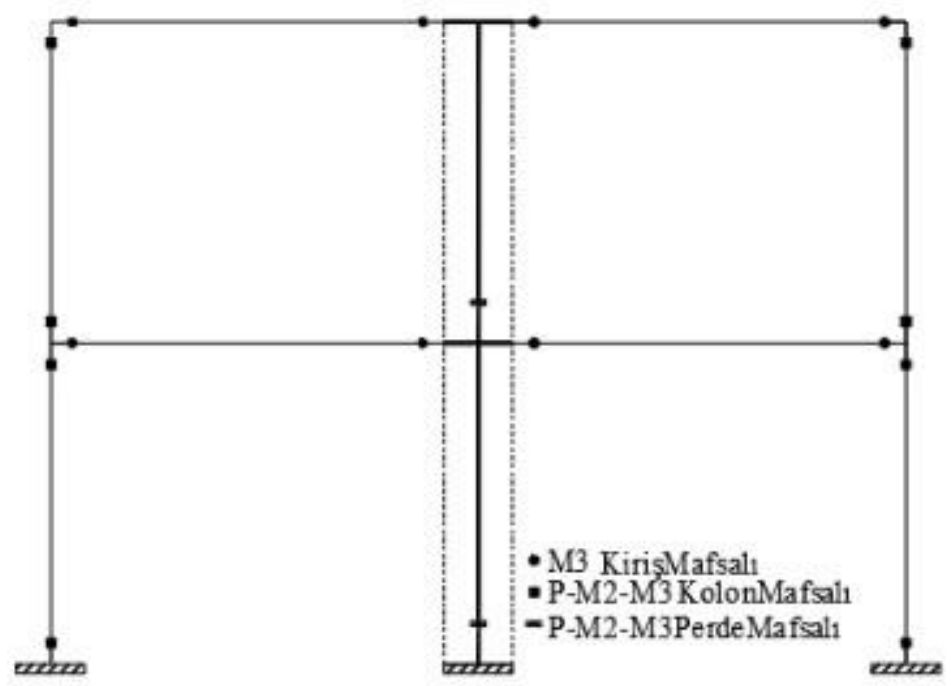

Şekil 7. Plastik mafsalların konumu

Plastik mafsal boyu, kolon ve kiriş elemanlarda DBYBHY (2007)'e göre kesit yüksekliğinin yarısı olarak tanımlanmıştır. Perde elemanlarda ise, Paulay ve Priestley (1992) tarafından önerilen ve Eşt. 4 'te verilen plastik mafsal boyu ifadesi kullanılmıştır.

$L_{p}=0,08 \cdot z+0,022 \cdot d_{b} \cdot f_{y}$

Burada; $L_{p}$, plastik mafsal boyunu; $z$, moment sıfır noktasının temel üstü yüksekliğini; $f_{y}$, boyuna donatının akma dayanımını; $d_{b}$, boyuna donatı çapını ifade etmektedir.

\section{Araştırma Sonuçları ve Tartışma}

\subsection{Bina Performansının Belirlenmesi}

Oluşturulan betonarme bina modellerinin deprem güvenliği, “Artımsal Eşdeğer Deprem Yükü Yöntemi” kullanılarak belirlenmiştir. Kütlelerle uyumlu düşey yükler altında doğrusal olmayan statik analiz ile çözümlenen modellerin analiz sonuçları, yatay yük uygulanan artımsal itme analizinin başlangıç koşulları olarak dikkate alınmıştır. Doğrusal olmayan itme analizlerinde, birinci mod titreşim şekli ile uyumlu olarak deprem yükü uygulanmış ve koordinatları "taban kesme kuvveti-tepe yerdeğiştirmesi" 
olan kapasite eğrileri elde edilmiştir. Kapasite eğrilerini oluşturan düşey eksen bina ağırlığı ile yatay eksen ise bina yüksekliği ile oranlanarak grafikler boyutsuz hale getirilmiştir. Perde duvar yerleşiminin boyutsuzlaştırılmış kapasite eğrileri üzerindeki etkinliğinin incelenmesi için, aynı perde miktarına ve açıklık sayısına sahip modeller birbiri ile kıyaslanmışıtır. Bu amaçla; iki açıklıklı iki perdeli Model 2_A2_P2 ve Model 3_A2_P2, iki açıklıklı dört perdeli Model 4_A2_P4 ve Model 5_A2_P4 ve dört açılıklı altı perdeli Model 7_A4_P $\overline{6}$ ve Model 8_A4_P $\overline{6}$ binalarına ait sonuçlar Şekil 8'de verilmiş̧tir.

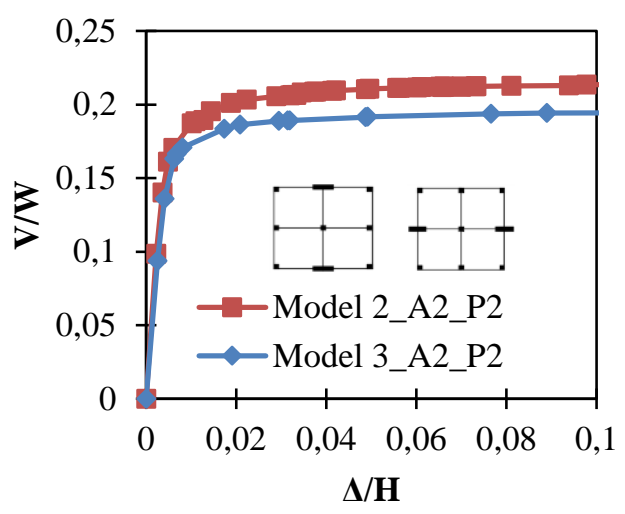

(a) İki açıklıklı iki perdeli modeller

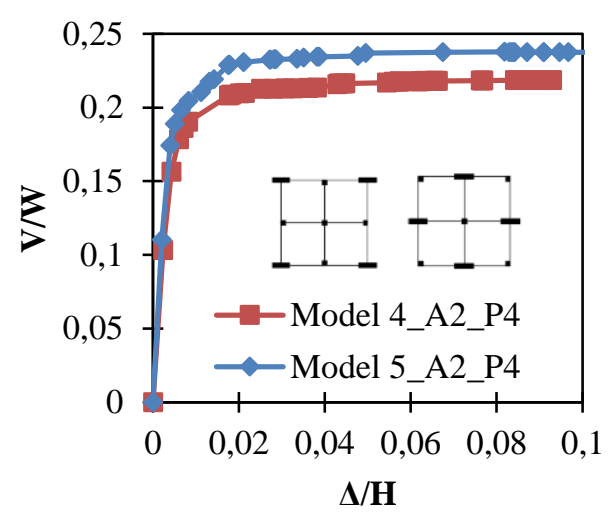

(b) İki açıklıklı dört perdeli modeller

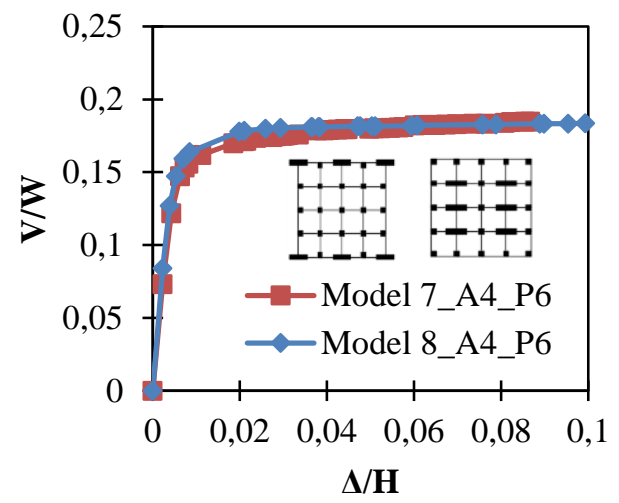

(c) Dört açıklıklı altı perdeli modeller

\section{Şekil 8. Perde yeri değişiminin kapasite ĕgrisi üzerindeki etkisi}

Şekil 8'deki grafikler incelendiğinde perde duvar yerinin değişiminin kapasite eğrisi üzerinde önemli bir değiş̧ime neden olmadığı görülmüştür. Perde elemanların dış aksa yerleştirildiği $2 \times 2$ açıklıklı iki perdeli bina modelinin (Model 2_A2_P2), iç aksa yerleştirilen bina modelinden (Model 3_A2_P2) \%2 daha fazla kesme kuvveti taşıma kapasitesine sahip olduğu görülmüştür. $2 \times 2$ açıklıklı dört perdeli modellerde bu durum tam tersi olarak karşımıza çıkmaktadır. Yani perde duvarı iç aksa yerleştirilen bina modeli (Model 5_A2_P4) dış aksa yerleştirilen bina modeline (Model 4_A2_P4) göre \%2 daha fazla kesme kuvveti taşıma kapasitesine sahiptir. 4×4 açıklıklı altı perdeli modellerde (Model 7_A4_P6 ve Model 8_A4_P6) ise perde duvar yerinin değişimi binanın kesme kuvveti taşıma kapasitesini neredeyse hiç değiştirmemiştir.

Çözümlemeler sonucunda elde edilen tüm model binaların çatlamamış kesite ait birinci mod doğal titreşim periyodları $\left(T_{1}\right)$ ve hedef yerdeğiştirme istem değerleri ( $\left.\Delta_{\text {hedef }}\right)$ Tablo 1'de verilmiştir. Perdeli-çerçeveli bina modelleri için elde edilen doğal periyod ve hedef yerdeğiştirme istem değerleri, çerçeveli bina değerlerine oranlanarak değişim miktarları belirlenmiş̧tir.

Tablo 1. Binalara ait doğal periyod ve hedef yerde ğiştirme istem dĕ̆erleri

\begin{tabular}{cccccc}
\hline Model No & $\begin{array}{c}\text { Açıklık } \\
\text { Sayısı }\end{array}$ & $\begin{array}{c}\mathbf{T}_{\mathbf{1}} \\
(\mathrm{sn})\end{array}$ & $\mathbf{T}_{\mathbf{1}}$ oranı & $\begin{array}{c}\Delta_{\text {hedef }} \\
(\mathrm{mm})\end{array}$ & $\boldsymbol{\Delta}_{\text {hedef }}$ oranı \\
\hline Model 1_A2_C & & 0.94 & 1.00 & 433 & 1.00 \\
Model 2_A2_P2 & & 0.78 & 0.83 & 347 & 0.80 \\
Model 3_A2_P2 & $2 \times 2$ & 0.84 & 0.89 & 383 & 0.88 \\
Model 4_A2_P4 & & 0.77 & 0.82 & 352 & 0.81 \\
Model 5_A2_P4 & & 0.71 & 0.76 & 308 & 0.71 \\
\hline Model 6_A4_Ç & $4 \times 4$ & 1.11 & 1.00 & 523 & 1.00
\end{tabular}




\begin{tabular}{lllll} 
Model 7_A4_P6 & 0.91 & 0.82 & 420 & 0.80 \\
Model 8_A4_P6 & 0.86 & 0.77 & 384 & 0.73 \\
\hline
\end{tabular}

Periyod değeri; bina ağırlığı, kat adedi ve yatay yükler etkisi altındaki ötelenme rijitliğine bağlı olarak belirlenmektedir. Yatay yükler etkisindeki perdeli-çerçeveli sistemlerin yanal ötelenme rijitliği çerçeveli sistemlerinkine göre oldukça fazladır. Elde edilen sonuçlar genel olarak değerlendirildiğinde, perde miktarının artması ile bina doğal titreşim periyodunun ve hedef yerdeğiştirme istem değerinin azaldığı görülmüştür. Aynı perde miktarına sahip ancak yerleşimleri farklı olan bina modellerinin periyod ve hedef yerdeğiştirme istem değerleri farklılık göstermektedir. Bunun nedeni sistemde deprem doğrultusuna göre perde elemana bağlı olan kiriş elemanların sayısının farklı olmasıdır. Dış aksa yerleştirilerek tek taraftan kiriş bağlantısı bulunan sistemlerde rijitlik daha az olduğundan sistemin periyodu ve buna bağlı olarak hedef yerdeğiştirme istem değeri artmaktadır.

Perdeli-çerçeveli bina modellerinde, hedef yerdeğiştirme seviyesindeki perde duvarların taşıdığı toplam kesme kuvvetlerinin kat seviyesine göre dağılımı Şekil 9'da, toplam eğilme momenti dağılımı ise Şekil 10'da verilmiştir. Burada, Model 2_A2_P2, Model 4_A2_P4 ve Model 7_A4_P6 binaları perde duvarların genellikle dış akslara yerleștirildiği modelleri; Model 3_A2_P2, Model 5_A2_P4 ve Model 8_-A44_P6 binaları ise perde duvarların genellikle iç akslara yerleştirildiği modelleri temsil etmektedir. Moment grafikleri üzerinde yazan pozitif ve negatif değerler, en büyük moment değerlerini ifade etmektedir.

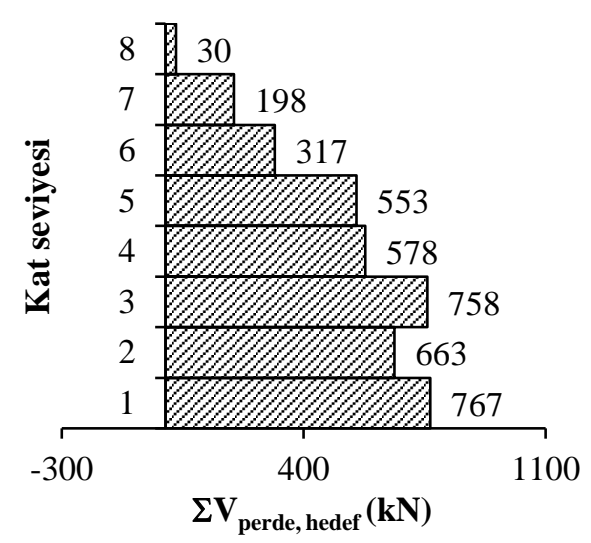

(a) Model 2_A2_P2

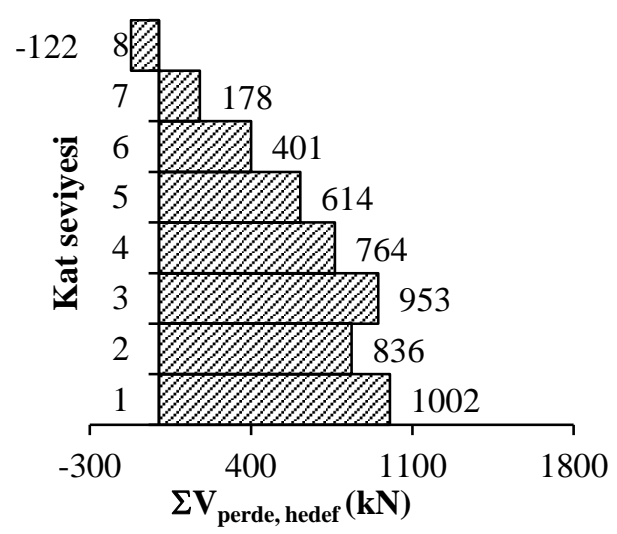

(c) Model 4_A2_P4

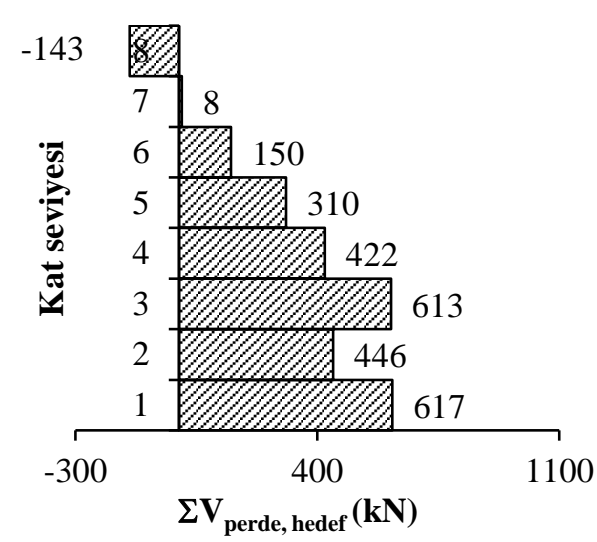

(b) Model 3_A2_P2

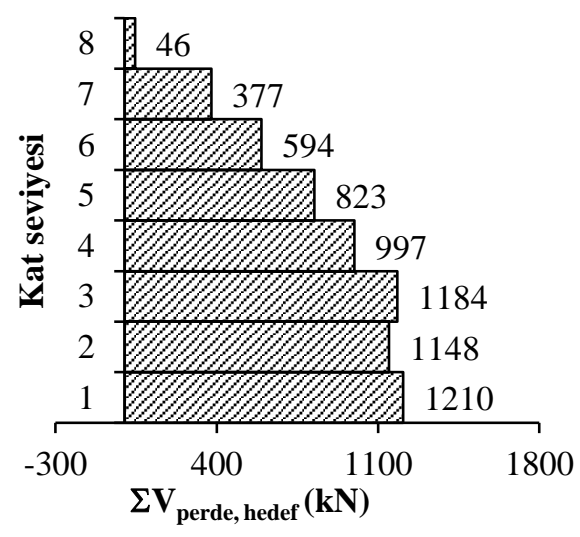

(d) Model 5_A2_P4 


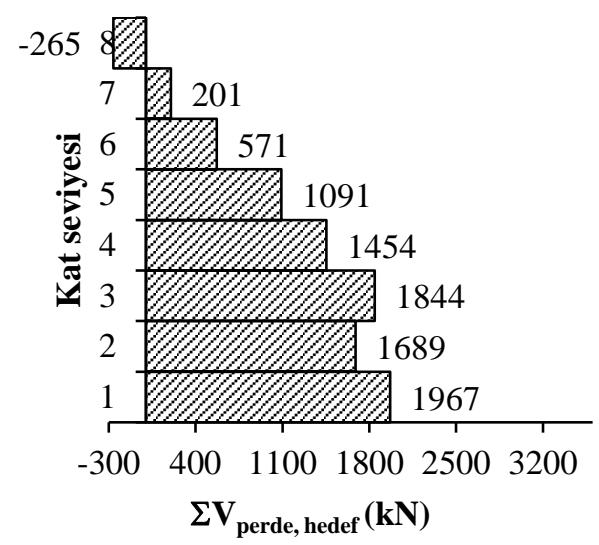

(e) Model 7_A4_P6

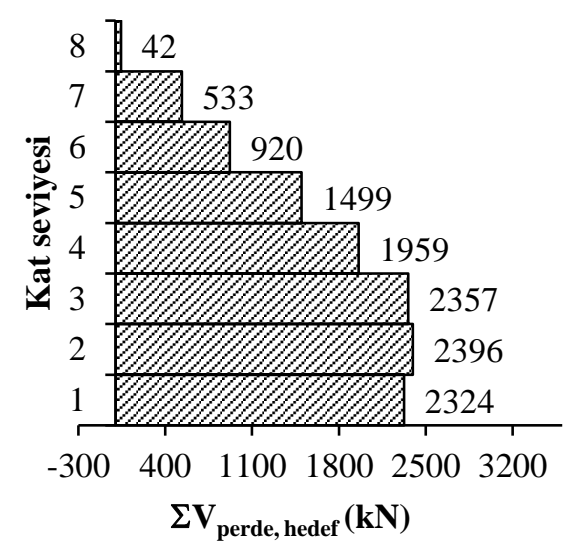

(f) Model 8_A4_P6

Şekil 92. Perde duvarlarda meydana gelen toplam kesme kuvveti dă̆gllımlarl

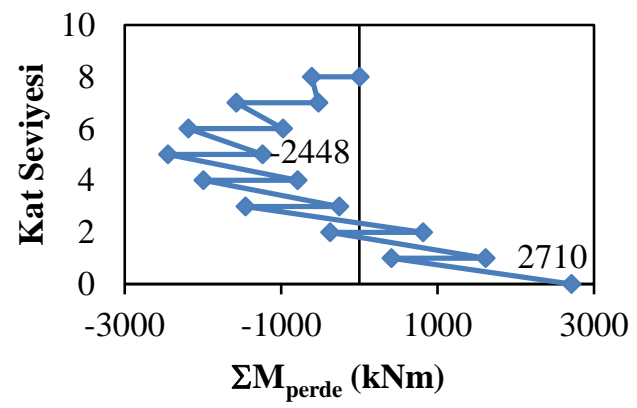

(a) Model 2_A2_P2

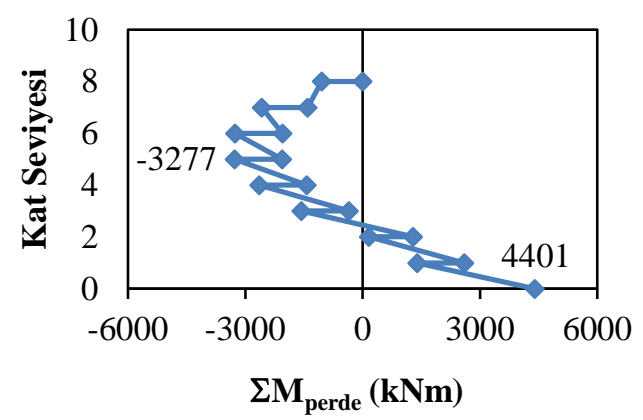

(c) Model 4_A2_P4

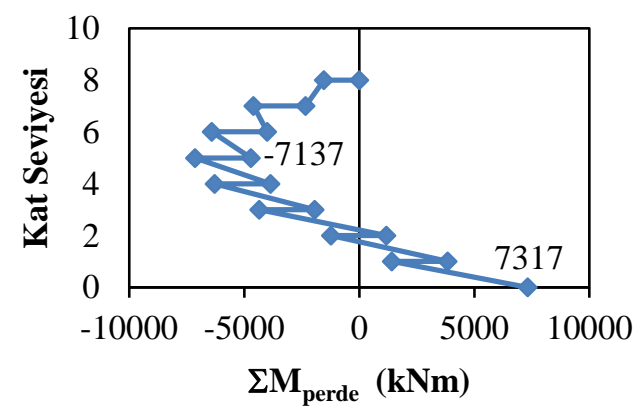

(e) Model 7_A4_P6

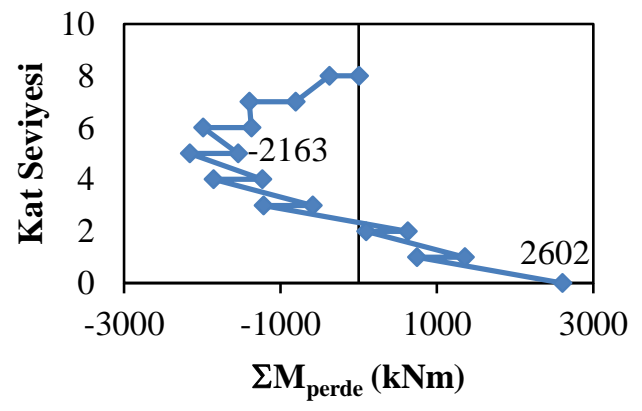

(b) Model 3_A2_P2

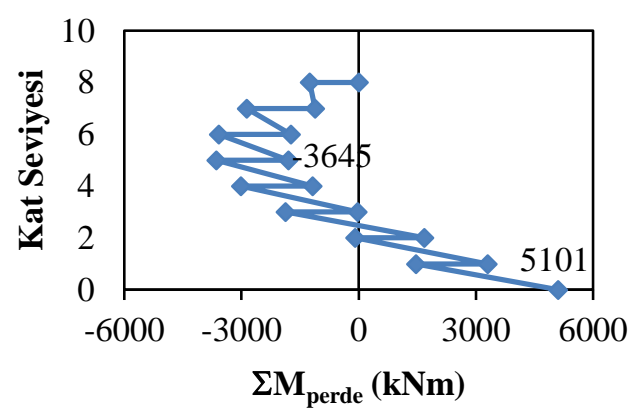

(d) Model 5_A2_P4

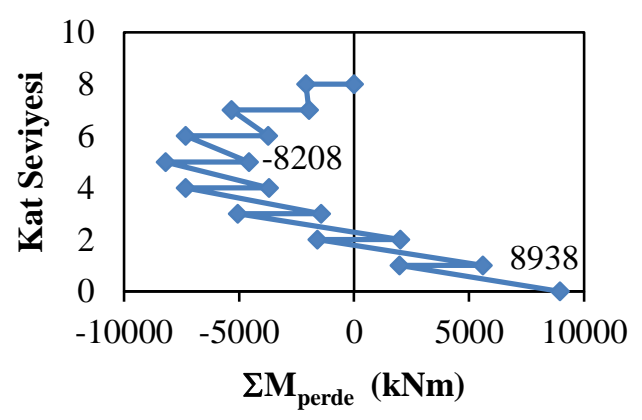

(f) Model 8_A4_P6

Şekil 103. Perde duvarlarda meydana gelen toplam moment dağgllımları 
Elde edilen sonuçlar incelendiğinde $2 \times 2$ açıklığa ve iki adet perde duvara sahip modelde perde duvarların diş aksa yerleştirilmesi durumunda perde duvarın taşıdığı kesme kuvveti ve moment değerinde artış meydana gelmiştir. Diğer tüm modellerde perde duvarın dış akslara yerleştirilmesi ile perde duvara ait kesme kuvveti ve moment değerlerinde azalma meydana gelmiştir. Ancak binada dikkat edilmesi gereken bir husus perde duvarın iç ve dış akslara yerleştirilmesi durumunda perde rijitliğinin kiriş bağlantılarından dolayı aynı olmamasıdır.

Perde duvarlar için elde edilen en büyük moment değeri birinci katta ortaya çıkmaktadır. Birinci katta bulunan perde duvarların taşıdığı toplam moment; deprem etkisinde ortaya çıkan devrilme momentine oranlanarak Tablo 2'de verilmiştir. Aynı tabloda, her bir model için elde edilen hedef yerdeğiştirme istem seviyesindeki kat kesme kuvveti değerleri ve bu kesme kuvvetinin perde duvarlar ve kolonlar arasındaki paylaşım miktarları da sunulmuştur. Devrilme momenti Eşt. 5 ile hesaplanmıştır. Burada, $M_{o}$, devrilme momentini; $H_{N}$, bina yüksekliğini ve $V_{\text {hedef, }}$ hedef yerdeğiştirme seviyesindeki taban kesme kuvvetini ifade etmektedir. Burada, doğrusal olmayan davranış esnasında depremin üçgen yayılı dağılışının değişmediği kabul edilmiştir.

$$
M_{o}=V_{\text {hedef }} \cdot \frac{2 H_{N}}{3}
$$

Tablo 2. Perdelerin taşıdiğ kesme kuvveti ve moment oranları

\begin{tabular}{cccccccc}
\hline Bina Modeli & $\begin{array}{c}\mathbf{V}_{\text {hedef }} \\
(k N)\end{array}$ & $\begin{array}{c}\mathbf{V}_{\text {cerceve }} \\
(k N)\end{array}$ & $\begin{array}{c}\mathbf{V}_{\text {perde }} \\
(\mathrm{kN})\end{array}$ & $\begin{array}{c}\mathbf{V}_{\text {perde }} / \mathbf{V}_{\text {hedef }} \\
(\%)\end{array}$ & $\begin{array}{c}\mathbf{M}_{\mathbf{0}} \\
(\mathrm{kNm})\end{array}$ & $\begin{array}{c}\mathbf{M}_{\text {perde }} \\
(\mathrm{kNm})\end{array}$ & $\begin{array}{c}\mathbf{M}_{\text {perde }} / \mathbf{M}_{\mathbf{0}} \\
(\%)\end{array}$ \\
\hline Model 2_A2_P2 & 1550 & 783 & 767 & 49 & 24798 & 2710 & 11 \\
Model 3_A2_P2 & 1513 & 895 & 617 & 41 & 24201 & 2596 & 11 \\
Model 4_A2_P4 & 1691 & 688 & 1002 & 59 & 27051 & 4401 & 16 \\
Model 5_A2_P4 & 1786 & 576 & 1210 & 68 & 28569 & 5100 & 18 \\
Model 7_A4_P6 & 4918 & 2951 & 1967 & 40 & 78681 & 7317 & 9 \\
Model 8_A4_P6 & 5088 & 2764 & 2324 & 46 & 81406 & 8938 & 11 \\
\hline
\end{tabular}

Binanın hedef yerdeğiştirme istem seviyesinde, perde duvarlar toplam kesme kuvvetinin $\% 40$ ile \% 68 arasındaki miktarını taşımaktadır. Elde edilen sonuçlardan görüldüğü gibi perde yeri değişiminin $\sum \mathrm{M}_{\text {perde }} / \mathrm{M}_{\mathrm{o}}$ oranı üzerindeki etkinliği oldukça düşük seviyelerde kalmıştır. Perde duvarın dış aksa yerleştirilmesi iki açıklıklı dört perdeli ve dört açıklıklı altı perdeli modellerde bu oranı $\% 2$ seviyesinde düşürürken iki açıklıklı iki perdeli modellerde herhangi bir değişime neden olmamıştır.

Tüm model binaların performans değerlendirmesi 50 yılda aşılma olasılığı \%10 olan deprem için yapılmıştır. Model binalarda, birinci kattaki düşey taşıyıcı elemanlara ait hasarın yüzdesel dağılımı ve elde edilen performans seviyeleri Tablo 3 'te verilmiştir.

Tablo 3. Hasar dağılımı ve bina performans seviyesi sonuçları

\begin{tabular}{cccccc}
\hline Model & $\begin{array}{c}\text { Minimum } \\
\text { Hasar } \\
\text { Bölgesi }\end{array}$ & $\begin{array}{c}\text { Belirgin } \\
\text { Hasar } \\
\text { Bölgesi }\end{array}$ & $\begin{array}{c}\text { İleri } \\
\text { Hasar } \\
\text { Bölgesi }\end{array}$ & $\begin{array}{c}\text { Göçe } \\
\text { Bölgesi }\end{array}$ & $\begin{array}{c}\text { Performans } \\
\text { Seviyesi }\end{array}$ \\
\hline Model 1_A2_C & - & 69 & 31 & - & Göçme Öncesi \\
Model 2_A2_P2 & - & 100 & - & - & Can Güvenliği \\
Model 3_A2_P2 & - & 100 & - & - & Can Güvenliği \\
Model 4_A2_P4 & - & 100 & - & - & Can Güvenliği \\
Model 5_A2_P4 & - & 100 & - & - & Can Güvenliği \\
\hline Model 6_A4_C & - & - & 22 & 78 & Göçme Durumu \\
Model 7_A4_P6 & - & 93 & 7 & - & Can Güvenliği \\
Model 8_A4_P6 & - & 100 & - & - & Can Güvenliği \\
\hline
\end{tabular}

Konut türü binalardan beklenen performans hedefi 50 yllda aşılma olasıllı̆̆ $\% 10$ olan deprem için "Can Güvenliğì" seviyesidir. Çalışma kapsamında yapılan incelemelerde model olarak; aksları düzenli ve simetrik plana sahip çerçeveli binalar seçilmesine rağmen, hedef performans seviyesinin sağlanmadığı görülmüştür. Sisteme perde duvar yerleştirilmesi ile tüm modellerde, hedef performans seviyesi sağlanmıştır. Dolayısıyla yüksek katlı binaların alt sınıı olarak belirtebileceğimiz sekiz katlı binaların tasarımında mutlaka perde duvar yerleştirilmesi gerektiği söylenebilir. Perde duvar yerleştirilmesi ile binanın performans seviyesi yükseltilebilmektedir. Tablo 3'te elde edilen sonuçlar değerlendirildiğinde, perde duvar yerleştirilmesi ile düssey taşıyıcı elemanların hasarının azaldığı görülmüştür. Perde yerinin değişiminin ise, eleman hasar yüzdelerinde ve bina performans seviyesinde önemli bir etkisi olmamıştır. 


\section{Sonuç}

Yapılan çalışmada kapsamında; farklı açıklık sayısına sahip konut türü sekiz katlı, simetrik ve düzenli taşıyıcı sisteme sahip betonarme çerçeveli binalar model olarak seçilmiştir. Bu binalara farklı miktar ve yerleşimde perde duvarlar ilave edilerek perdeliçerçeveli taşıyıcı sistemler oluşturulmuştur. Tüm model binaların deprem performans değerlendirmeleri doğrusal elastik olmayan yöntemlerden "Artımsal Eşdeğer Deprem Yükü Yöntemi” kullanılarak yapılmıştır. Yapılan çözümlemelerden elde edilen sonuç ve öneriler aşağıda sunulmuştur.

1. Bina planına yerleştirilen perde duvar miktarının artması ile kat kesme kuvveti kapasitesinde ve V/W oranında artış meydana gelmiştir.

2. Betonarme perde duvarların bina planındaki yerinin değişiminin, binanın kapasite eğrisi üzerindeki etkinliği oldukça düşük seviyelerde kalmıştır. Perde duvarların iç ya da dış aksa yerleştirilmesi, binanın kesme kapasitesinde en fazla \%2 oranında bir değişime neden olmuştur. Açıklık sayısının fazla olduğu modelde bu etki neredeyse hiç gözlenmemiştir.

3. Perde miktarııın artması ile bina doğal titreşim periyodu ve hedef yerdeğiştirme istem değerleri beklendiği gibi azalmaktadır. Aynı perde miktarına sahip ancak plandaki yerleşimleri farklı olan bina modellerinin periyod ve hedef yerdeğiştirme istem değerleri, iki açıklıklı iki perdeli modellerde perde duvarın iç akslara yerleştirildiği, iki açıklıklı dört perdeli ve dört açıklıklı altı perdeli modellerde ise dış akslara yerleştirildiği binalarda daha büyük olarak elde edilmiştir. Periyod ve hedef yerdeğiştirme istem değerlerinin daha büyük olarak elde edildiği tüm modeller incelendiğinde, perde duvara bağlı olan kiriş elemanların sayısının daha fazla olduğu görülmektedir. Dolayısıyla, aynı miktarda ancak tek taraftan kiriş bağlantısı bulunan perde duvara sahip sistemlerde iki taraftan kiriş bağlantısı bulunan sistemlere göre, yanal ötelenme rijitliği daha az olduğundan sistemin periyodu ve hedef yerdeğiştirme istem değerleri daha büyük olarak elde edilmektedir. Buradan aynı miktarda perde duvara sahip binalarda perde duvara bağlantısı sağlanan kirişlerin sayısının ve rijitliğinin önemli olduğu söylenebilir.

4. Aynı gözlemler perde duvarların taşıdığı toplam kesme kuvveti ve moment değerleri için de söylenebilir. Sadece $2 \times 2$ açıklığa ve iki adet perde duvara sahip modelde, perde duvarların dış aksa yerleştirilmesi durumunda, perde duvarın taşıdığı kesme kuvveti ve moment değerinde artış meydana gelmiştir. Diğer tüm modellerde perde duvarın iç akslara yerleştirilmesi durumunda kesme kuvveti ve moment değerlerinde artma meydana gelmiştir. Bu farklılık yine perde duvara deprem doğrultusunda bağlı olan kiriş sayısı ile ilgilidir.

5. Perde duvarlar için elde edilen kesme kuvveti, bazı durumlarda alt katta üst kattan daha küçük olarak elde edilmektedir. Bunun nedeni alt kattaki perdede plastik mafsal oluşumundan dolayı rijitliğinin azalması ve kattaki kuvvet dağılımının değişerek perde duvar üzerine etki eden kesme kuvvetinin azalmasıdır.

6. Binanın hedef yerdeğiştirme istem seviyesinde, perde duvarlarda elde edilen momentin en büyük değeri birinci katta ortaya çıkmaktadır. Perdeli çerçeveli binalardaki perde duvar moment değeri, çerçevenin etkisi ile üst katlarda işaret değiştirmektedir.

7. Hedef yerdeğiştirme istem seviyesindeki birinci kat kesme kuvvetinin oluşturduğu toplam devrilme momentinin $\% 9$ ile $\% 18$ arasındaki miktarı perde duvarlar tarafından karşılanmıştır. Perdelerin karşıladığı momentin toplam devrilme momentine oranının $\left(\sum \mathrm{M}_{\text {perde }} / \mathrm{M}_{\mathrm{o}}\right)$ en büyük değeri, iki açıklıklı dört perdeli sistemde elde edilmiştir. Bunun nedeni, toplam perde momentindeki artışın devrilme momentindeki artıştan daha fazla olarak elde edilmesidir. Kat alanının büyümesi, kolon sayısı ve kat kesme kuvveti kapasitesinin artmasına dolaylı olarak devrilme momentinin artmasına neden olmaktadır. Burada, Model 7 ve Model 8'de perde miktarı ve perdelerin taşıdığı toplam moment değeri en büyük olmasına rağmen, kat kesme kuvvetine bağlı olarak devrilme momenti değeri de arttığı için, $\Sigma \mathrm{M}_{\text {perde }} / \mathrm{M}_{\mathrm{o}}$ oranı yine \%10 mertebesinde elde edilmiştir.

8. Yapılan çözümlemelerde sekiz katlı ve taşıyıcı sistemi salt çerçeveli olarak oluşturulan bina modellerinin hiçbirinin hedef performans seviyesini sağlamadığı görülmüştür. Bina planına simetrik olarak perde duvar yerleştirilmesi, performans seviyesinin hedef performans seviyesine yükseltilmesini sağlamıştır. Dolayısıyla perde miktarı ve yerleşimi değiştirilen tüm bina çözümlemelerinde, "Can Güvenliği” performans seviyesi elde edilmiştir. Perde duvar yerinin değiş̧iminin, eleman hasar yüzdelerinde ve bina performans seviyesinde önemli bir etkisi olmamıştır.

\section{Kaynakça}

Aktan, S., \& Kıraç, N. (2010). Betonarme Binalarda Perdelerin Davranışa Etkileri. Eskişehir Osmangazi Üniversitesi Mühendislik Mimarlık Fakültesi Dergisi , 15-32.

Aracı, E. (2012). Yüksek Lisans Tezi. Betonarme Perde Konumlarının Bina Deprem Performansına Olan Etkisinin Bilgisayar Destekli İrdelenmesi. Antalya: Akdeniz Üniversitesi Fen Bilimleri Enstitüsü.

Atımtay, E. (2000). Açıklamalar ve Örneklerle Afet Bölgelerinde Yapılacak Yapılar Hakkında Yönetmelik (Betonarme Yapılar) (Cilt 1 ve 2). Ankara: Bizim Büro Basımevi Yayın Dağıtım San. Tic. Ltd. Şti.

Atımtay, E. (2001). Çerçeveli Ve Perdeli Betonarme Sistemlerin Tasarımı, Temel Kavramlar Ve Hesap Yöntemleri (Cilt 1 ve 2). Ankara: METU Press.

BESAM, Betonarme Elemanlarda Sargı ve Modelleme (2013). Türkiye Bilimsel ve Teknik Araştırma Grubu, Proje No, 111 M119. DBYBHY. (2007). Deprem Bölgelerinde Yapılacak Binalar Hakkında Yönetmelik. ANKARA: Bayındırlık ve İskan Bakanlığı. DELOP, Doğrusal Elastik Olmayan Değerlendirme (2013). Türkiye Bilimsel ve Teknik Araştırma Grubu, Proje No, 111M119.

Fahjan, Y. M., Başak, K., Kubin, J., \& Tan, M. T. (2011). Perdeli Betonarme Yapılar İçin Doğrusal Olmayan Analiz Metodları. Yedinci Ulusal Deprem Mühendisliği Konferansı. İstanbul. 
Firoozabad, E., Rao, K., \& Bagheri, B. (2012). Proc. of Int. Conf. on Advances in Civil Engineering. Effect of Shear Wall Configuration on Seismic Performance of Building, (s. 121-125).

Günel, A. O. (2013). Yüksek Lisans Tezi. Influence of the Shear Wall Area to Floor Area Ratio on the Seismic Performance of Existing Reinforced Concrete Buildings. Ankara: Orta Doğu Teknik Üniversitesi Fen Bilimleri Enstitüsü.

Halkude, S., Konapure, C., \& Birajdar, S. (2015). Effect of Location of Shear Walls on Seismic Performance of Buildings. International Journal of Current Engineering and Technology , 826-833.

Kasap, H., \& Varol, C. (2003). Perdeli-Çerçeveli Sistemlerde Planda Perde Yerinin Değişmesinin Perdeler ve Çerçeveler Arasındaki Kesme Kuvveti Dağılımına Etkisi. SAU Fen Bilimleri Enstitüsü Dergisi, 7((1)), 190-197.

Kasap, H., Mert, N., Sevim, E., \& Şeber, B. (2015). Perdeli-Çerçeveli Taşıyıcı Sistemli Binalarda Taşıyıcı Sistem Seçiminin Yapı Davranışı Üzerindeki Etkisinin İncelenmesi. APJES III-I, 3(1), 48-55 .

Öztürk, A., Çağlar, N., Dok, G., \& Yüksel, M. (2017). Fifth International Symposium on Innovative Technologies in Engineering and Science. Betonarme Perdelerin Betonarme Yüksek Yapıların Deprem Performansına Etkisi, (s. 1883-1892). BaküAzerbaycan.

Öztürk, T. (2005, Nisan). İMO İstanbul Şubesi 2005 İlkbahar-Yaz Dönemi Meslekiçi Eğitim Kursları. Betonarme Binalarda Deprem Perdelerinin Yerleşimi ve Tasarımı.

Paulay, T., \& Priestley, M. (1992). Seismic Design of Reinforced Concrete and Masonry Structures. United States of America: John Wiley \& Sons Inc.

Rokanuzzaman, M., Khanam, F., Das, A., \& Chowdhury, S. (2017). Effective Location of Shear Wall on Performance of Building Frame Subjected to Lateral Loading. International Journal of Advances in Mechanical and Civil Engineering, 51-54.

Sakcalı, G. B., Tekeli, H., \& Demir, F. (2017). Betonarme Binalardaki Perde Duvar Miktarının Bina Performansına Etkisi. Sakarya Üniversitesi Fen Bilimleri Enstitüsü Dergisi, 157-167.

SAP 2000, Structural Analysis Program, (2011). Computers and Structures, Inc., v.17.0.0., Berkeley, CA, United States of America

Sayın, E., Yön, B., \& Calayır, Y. (2010). Perde Konumunun ve Zemin Sınıfının Betonarme Yapılardaki Hasar Oranına Etkisi. Erciyes Üniversitesi Fen Bilimleri Enstitüsü Dergisi, 26(1), 1-6.

Şahin, H., Alyamaç, K., \& Erdoğan, A. (2013). Perdeli Çerçeveli Yapılarda Zemin Sınıfı ve Kat Adedi Dikkate Alınarak Gerekli Perde Oranının Tespiti. SDU International Technologic Science, 74-86.

Uçar, T., \& Merter, O. (2009). Planda Perde Yerleşiminin Betonarme Perde-Çerçeveli Binaların Deprem Davranışına Etkisi. DEÜ

Yaman, S. (2018). Yüksek Lisans Tezi. Perde Duvarlı Betonarme Binaların Deprem Güvenliği. Isparta: Süleyman Demirel Üniversitesi Fen Bilimleri Enstitüsü.

Yüksel, M., Çağlar, N., Dok, G., \& Demir, A. (2017). Fifth International Symposium on Innovative Technologies in Engineering and Science. Betonarme Yüksek Yapıların Deprem Performansına Betonarme Perde Oranın Etkisi, (s. 1893-1901). BaküAzerbaycan. 